Check for updates

Cite this: RSC Adv., 2018, 8, 10644

Received 18th January 2018

Accepted 28th February 2018

DOI: $10.1039 / c 8 r a 00531 a$

rsc.li/rsc-advances

\section{A correlation study of biological activity and molecular docking of Asp and Glu linked bis- hydrazones of quinazolinones $\uparrow$}

\begin{abstract}
H. K. Kumara, R. Suhas, D. M. Suyoga Vardhan, M. Shobha and D. Channe Gowda (DD *
The present investigation involves the synthesis and spectroscopic and biological activity studies of the bishydrazones of quinazolinones derived from aspartic acid and glutamic acid. The antioxidant activities of the compounds were evaluated using DPPH, DMPD and ABTS radical scavenging assays whose results revealed that the $\mathrm{IC}_{50}$ of compounds $6,7,11,12,20,21,25$ and 26 was lower than those of the standard references. The anti-inflammatory activity was evaluated with a haemolysis assay using a human blood erythrocytes suspension and the results demonstrated that compounds 8, 9, 13, 14, 22, 23, 27 and 28 were excellent anti-inflammatory agents. In addition, the antibacterial and antifungal activities against various clinical pathogens of human origin revealed that compounds 7, 9, 12, 14, 21, 23, 26 and 28 possessed potent antimicrobial properties. Furthermore, to understand the correlation between biological activity and drug-receptor interaction, molecular docking was performed on the active sites of tyrosine kinase (PDB ID: 2HCK), cyclooxygenase-2 (PDB ID: 1CX2) and glucosamine-6-phosphate (GlcN-6-P) synthase (PDB ID: 2VF5) which showed good binding profiles with the targets that can potentially hold the title compounds. The correlation study revealed that compounds containing EDGs $\left(-\mathrm{OH},-\mathrm{OCH}_{3}\right)$ were excellent antioxidants, compounds with EWGs $\left(-\mathrm{Cl},-\mathrm{NO}_{2}\right)$ exhibited good anti-inflammatory activity and compounds bearing $-\mathrm{OH}$ and $-\mathrm{NO}_{2}$ groups were very good antimicrobials.
\end{abstract}

\section{Introduction}

Computational biology and bioinformatics play a major role in designing drug molecules and have the potential to speed up the drug discovery process. Molecular docking of the drug molecule with the receptor gives important information about drug-receptor interactions and is commonly used to find out the binding orientation of drug candidates to their protein targets in order to predict the affinity and activity. ${ }^{\mathbf{1}}$ Medicinal chemistry is a specialized science that has evolved to encompass a broad range of disciplines concerned with the identification, synthesis and development of drug-like compounds for therapeutic use. It needs a wide range of expertise, developed through years of training, dedication and learning from best practice in order to produce drugs that are good enough to enter clinical trials with patients. ${ }^{2}$

Quinazolinones and their derivatives are building blocks of approximately 150 naturally occurring alkaloids isolated from plants, animals and microorganisms. The quinazolinone nucleus has diverse pharmacological activities, including

Department of Studies in Chemistry, University of Mysore, Manasagangotri, Mysuru570 006, Karnataka, India. E-mail: dchannegowda@yahoo.co.in; Tel: +91 821 2419664

$\dagger$ Electronic supplementary information (ESI) available. See DOI: 10.1039/c8ra00531a antimicrobial, ${ }^{3}$ anti-inflammatory, ${ }^{4}$ antimalarial, ${ }^{5}$ anticonvulsant, ${ }^{6}$ antihypertensive, ${ }^{7}$ anti-diabetic, ${ }^{8}$ PARP inhibitory ${ }^{9}$ and anticancer activity. ${ }^{10}$ On the other hand, hydrazones are present in many bioactive heterocyclic compounds and are of wide interest because of their diverse biological and clinical applications. Moreover, hydrazones of quinazolinone derivatives exhibited enhanced biological activity, viz. antimicrobial, ${ }^{\mathbf{1 1}}$ antiinflammatory, ${ }^{12}$ antiviral, ${ }^{13}$ analgesic ${ }^{14}$ and anticancer activity. ${ }^{15}$ The structures of the biologically active quinazolinonehydrazones are shown in Fig. 1.

Besides these, amino acids are endogenous substances which could be used for the modification of drug skeletons to promote the absorption of drugs. ${ }^{16}$ In addition, the toxicity of drugs also could be reduced via the introduction of amino acids. ${ }^{17}$ Conjugation of amino acids/peptides with heterocycles, ${ }^{18,19}$ especially with a quinazolinone moiety, ${ }^{20-22}$ enhances the overall therapeutic properties of the molecule. Motivated by the aforementioned literature and the recent encouraging results from our research group ${ }^{23-25}$ we have directed systematic efforts towards the synthesis of new bis-hydrazones of Asp and Glu linked quinazolinone derivatives followed by the study of their antimicrobial, antioxidant and anti-inflammatory activity. In addition, the results obtained were correlated with molecular docking studies in order to obtain some information about the binding efficiency and target interactions. The above are all collectively presented in this communication. 
<smiles>[R]Oc1cccc(/C=N/n2c(-c3ccccc3)nc3ccccc3c2=O)c1</smiles><smiles>[R]C([R2])=NNc1nc2ccccc2c(=O)n1C1CCCCC1</smiles>

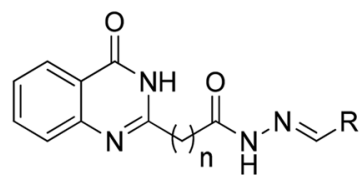<smiles>O=c1c2ccccc2nc(-c2ccco2)n1/N=C/C=C/c1ccccc1</smiles>

Fig. 1 The structures of the biologically active quinazolinone-hydrazones.

\section{Results and discussion}

\subsection{Chemistry}

The synthesis of the desired compounds was achieved according to the steps illustrated in Scheme 1. 3-(4-Oxo-3,4dihydroquinazolin-2-yl)propanoic acid (QZN 1) and 4-(4-oxo3,4-dihydroquinazolin-2-yl)butanoic acid (QZN 2) were synthesized by literature known methods. ${ }^{26-28}$ Conjugation of QZN 1/QZN 2 with $p$-TsOH $\cdot \mathrm{NH}_{2}-\mathrm{Asp}(\mathrm{OBzl})-\mathrm{OBzl} / \mathrm{HCl} \cdot \mathrm{NH}_{2}-$ $\mathrm{Glu}\left(\mathrm{OCH}_{3}\right)-\mathrm{OCH}_{3}$ was carried out using EDCI/HOBt as the coupling agent and NMM as the base to obtain 1, 2, 15 and 16. Next, these conjugates were refluxed with an excess of hydrazine hydrate to obtain the corresponding bis-hydrazides of the quinazolinones, 3, 4, 17 and 18. These bis-hydrazides were allowed to react with various substituted aldehydes to obtain the bishydrazones of the quinazolinone derivatives, 5-14 and 19-28. All the compounds were obtained in good yields. The structures of all the newly synthesized compounds were confirmed by IR, ${ }^{1} \mathrm{H}-\mathrm{NMR},{ }^{13} \mathrm{C}-\mathrm{NMR}$ and mass spectral analyses. The conjugation of the quinazolinones with the amino acids was confirmed by the appearance of an $-\mathrm{NH}$ peak at $\delta 8.54-8.15$ and the absence of a COOH signal at $\delta 12.25$ in the ${ }^{1} \mathrm{H}$ NMR spectrum. In the IR spectra, bands appeared at $3310 \mathrm{~cm}^{-1}\left(-\mathrm{NH}_{2}\right)$ and $3217 \mathrm{~cm}^{-1}$ $(-\mathrm{NH})$ and in the PMR spectra, peaks appeared at $\delta 4.12-3.26$
$\left(-\mathrm{NH}_{2}\right)$ and 9.11-8.88 $(-\mathrm{NH})$ which indicated the conversion of an ester into a hydrazide. The formation of the hydrazones $(-\mathrm{N}=\mathrm{CH})$ was confirmed by the presence of an absorption band at $1612-1630 \mathrm{~cm}^{-1}$ and a peak at $\delta 8.62-8.30$. The presence of all requisite peaks and absence of extraneous peaks in the PMR and CMR spectra confirm the structures. Furthermore, the mass values obtained were in good agreement with the structures assigned (spectral data are provided in the ESI $\dagger$ ).

\subsection{Biology}

2.2.1. Antioxidant activity. The in vitro antioxidant activity of the synthesized compounds was evaluated with $\mathrm{DPPH},{ }^{29}$ DMPD, ${ }^{30,31}$ and $\mathrm{ABTS}^{32}$ radical scavenging assays. The values were determined in terms of the $\mathrm{IC}_{50}$, the concentration at which $50 \%$ of the radicals were scavenged, and were calculated to evaluate the antioxidant activity. The $\mathrm{IC}_{50}$ values were compared with those of the standards: ascorbic acid (AA) and gallic acid (GA). The results are tabulated in Table 1.

Most of the synthesized compounds showed antioxidant properties in all three radical scavenging assays. The conjugations of the QZN moiety with Asp (1 and 2) and Glu (15 and 16) showed antioxidant properties at higher concentrations which is in accordance with our earlier observations. ${ }^{33}$ Conversion of

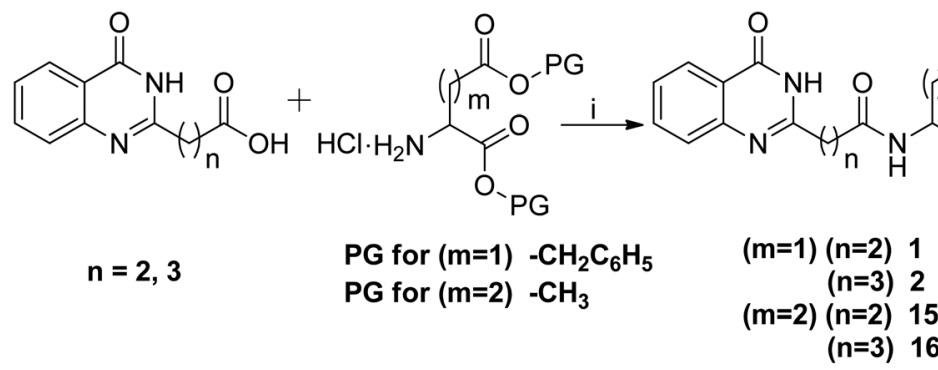<smiles>CC(C)C(=O)OOC(=O)C(=O)OP=O</smiles>
$(n=2)$
$(n=3)$ $(n=3) 16$

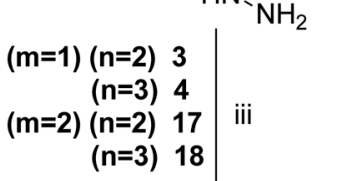

$\mathbf{R}$<smiles>[R]c1ccccc1</smiles><smiles>COc1cc(C)cc(OC)c1OC</smiles>

$5,10,19,24$

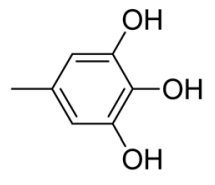

$7,12,21,26$
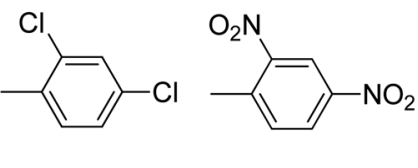

$8,13,22,27$

$9,14,23,28$

Scheme 1 Bis-hydrazones of quinazolinone derived from anionic amino acid linkers. Reagents and conditions: (i) $\mathrm{NMM}, \mathrm{EDCl} / \mathrm{HOBt}, 0{ }^{\circ} \mathrm{C}$ to $\mathrm{rt}$, (ii) $\mathrm{NH}_{2} \mathrm{NH}_{2} \cdot \mathrm{H}_{2} \mathrm{O}$, ethanol, reflux, $16 \mathrm{~h}$, (iii) $\mathrm{R}-\mathrm{CHO}$, EtOH, reflux, 7-8 h. 
Table 1 Antioxidant activity and docking studies of the synthesized quinazolinone derivatives ${ }^{a}$

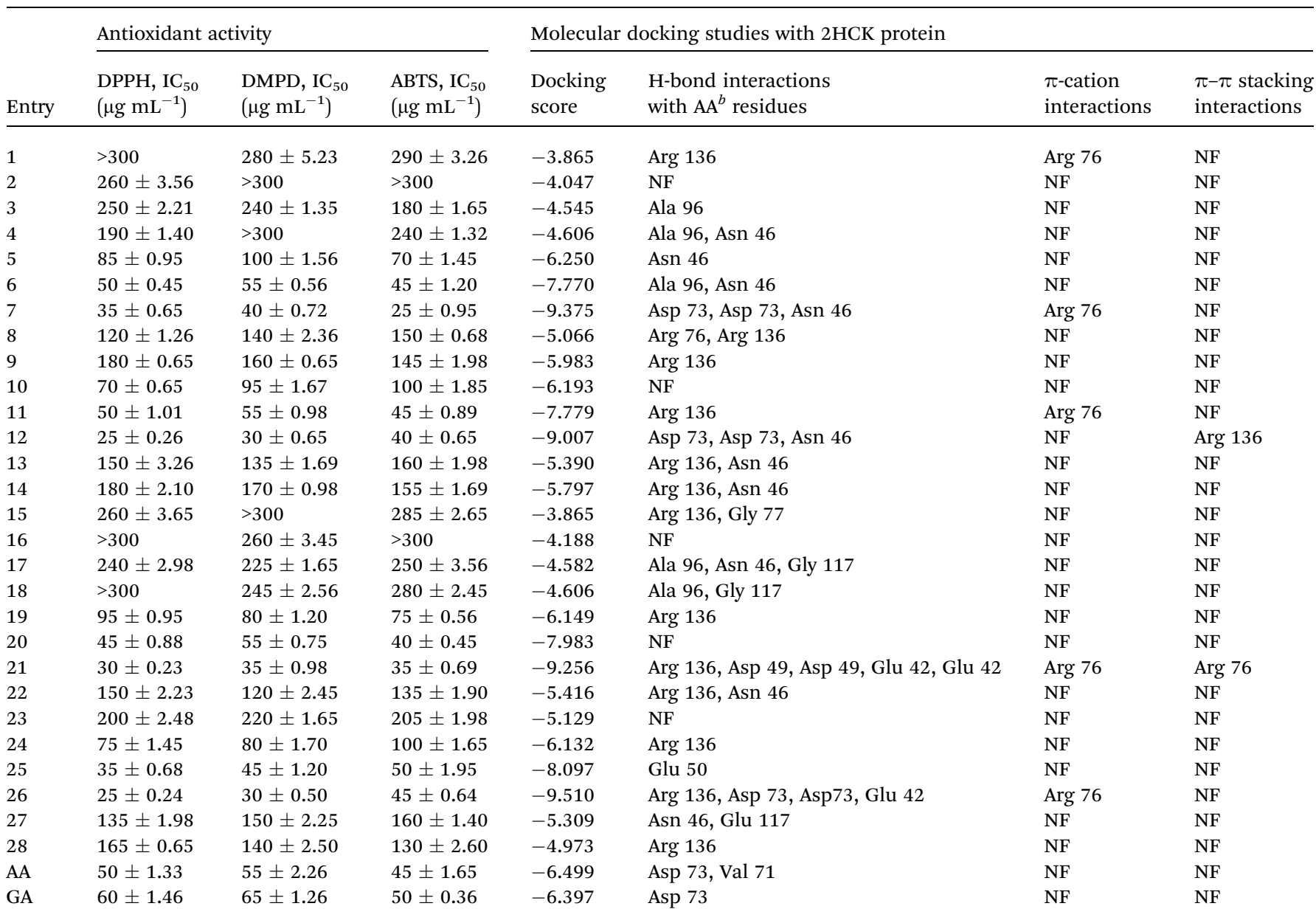

${ }^{a}$ The values are the means of three determinations, the ranges of which are $<5 \%$ of the mean in all cases. ${ }^{b}$ Amino acid; NF: not formed, AA $=$ ascorbic acid, GA = gallic acid.

the esters into hydrazides $(\mathbf{3}, \mathbf{4}, \mathbf{1 7}$ and $\mathbf{1 8})$ slightly improved the antioxidant potential, which may be due to the radical scavenging ability of $\mathrm{NH}-\mathrm{NH}_{2}$ groups. ${ }^{34}$ The enhanced activity of the resultant hydrazones could be due to the presence of groups on the phenyl ring. Those compounds that lack substituents on the phenyl ring $(5,10,19$ and 24) showed moderate antioxidant activity with $\mathrm{IC}_{50}$ values ranging from $70-100 \mu \mathrm{g} \mathrm{mL}^{-1}$. Compounds with electron donating substituents like $-\mathrm{OH}$ and $-\mathrm{OCH}_{3}$ on the phenyl ring $(6,7,11,12,20,21,25$ and 26) exhibited excellent radical scavenging activity with $\mathrm{IC}_{50}$ values ranging from $25-55 \mu \mathrm{g} \mathrm{mL}^{-1}$ in all three antioxidant assays and even better results compared to the standards AA (45-55 $\mu \mathrm{g}$ $\left.\mathrm{mL}^{-1}\right)$ and $\mathrm{GA}\left(50-65 \mu \mathrm{g} \mathrm{mL}{ }^{-1}\right)$. In addition, the presence of $\mathrm{OH}$ slightly improved the antioxidant activity compared to that with $\mathrm{OCH}_{3}$. In contrast, compounds with electron withdrawing groups like $-\mathrm{Cl}$ and $-\mathrm{NO}_{2}$ on the phenyl $\operatorname{ring}(\mathbf{8}, \mathbf{9}, \mathbf{1 3}, \mathbf{1 4}, \mathbf{2 2}, \mathbf{2 3}$, 27 and 28) showed the lowest antioxidant activity with $\mathrm{IC}_{50}$ values ranging from $120-220 \mu \mathrm{g} \mathrm{mL} \mathrm{m}^{-1}$. On the basis of the above observation, it may be stated that compounds containing EDGs are excellent antioxidants, ${ }^{35-37}$ whereas the presence of EWGs decreases the antioxidant potential of the synthesized analogues. ${ }^{22}$ With respect to the length of the alkyl chain in the QZNs, there was no significance for the antioxidant potential. Replacement of Asp with Glu makes the antioxidant activity even better.

2.2.2. Anti-inflammatory activity. The human erythrocyte suspension was used to evaluate the in vitro anti-inflammatory activity of the synthesized molecules by employing a literature known method. ${ }^{38} \mathrm{~A}$ substantial number of compounds exhibited excellent to moderate activity compared to the standards, indomethacin (IM) and ibuprofen (IP). The results of the $\mathrm{IC}_{50}$ measurements were determined and are tabulated in Table 2 . The compounds with electron withdrawing groups $(\mathbf{8}, \mathbf{9}, \mathbf{1 3}, \mathbf{1 4}$, 22, 23, 27 and 28) showed excellent activity with $\mathrm{IC}_{50}$ values of $45,25,50,45,50,40,45$ and $35 \mu \mathrm{g} \mathrm{mL} \mathrm{m}^{-1}$, respectively, which are more potent than those of indomethacin $\left(55 \mu \mathrm{g} \mathrm{mL}{ }^{-1}\right)$ and ibuprofen $\left(50 \mu \mathrm{g} \mathrm{mL}^{-1}\right)$. Besides this, compounds with electron donating substituents like $\mathrm{OH}$ and $\mathrm{OCH}_{3}(6,7,11,12,20,21,25$ and 26) or without any substituents $(5,10,19$ and 24) showed moderate activity. This clearly indicates that the compounds with electron withdrawing groups $\left(\mathrm{Cl}, \mathrm{NO}_{2}\right)$ on the phenyl ring are better anti-inflammatory agents. ${ }^{39}$ Furthermore, $\mathrm{NO}_{2}$ which 
Table 2 Anti-inflammatory activity and docking studies of the synthesized quinazolinone derivatives ${ }^{a}$

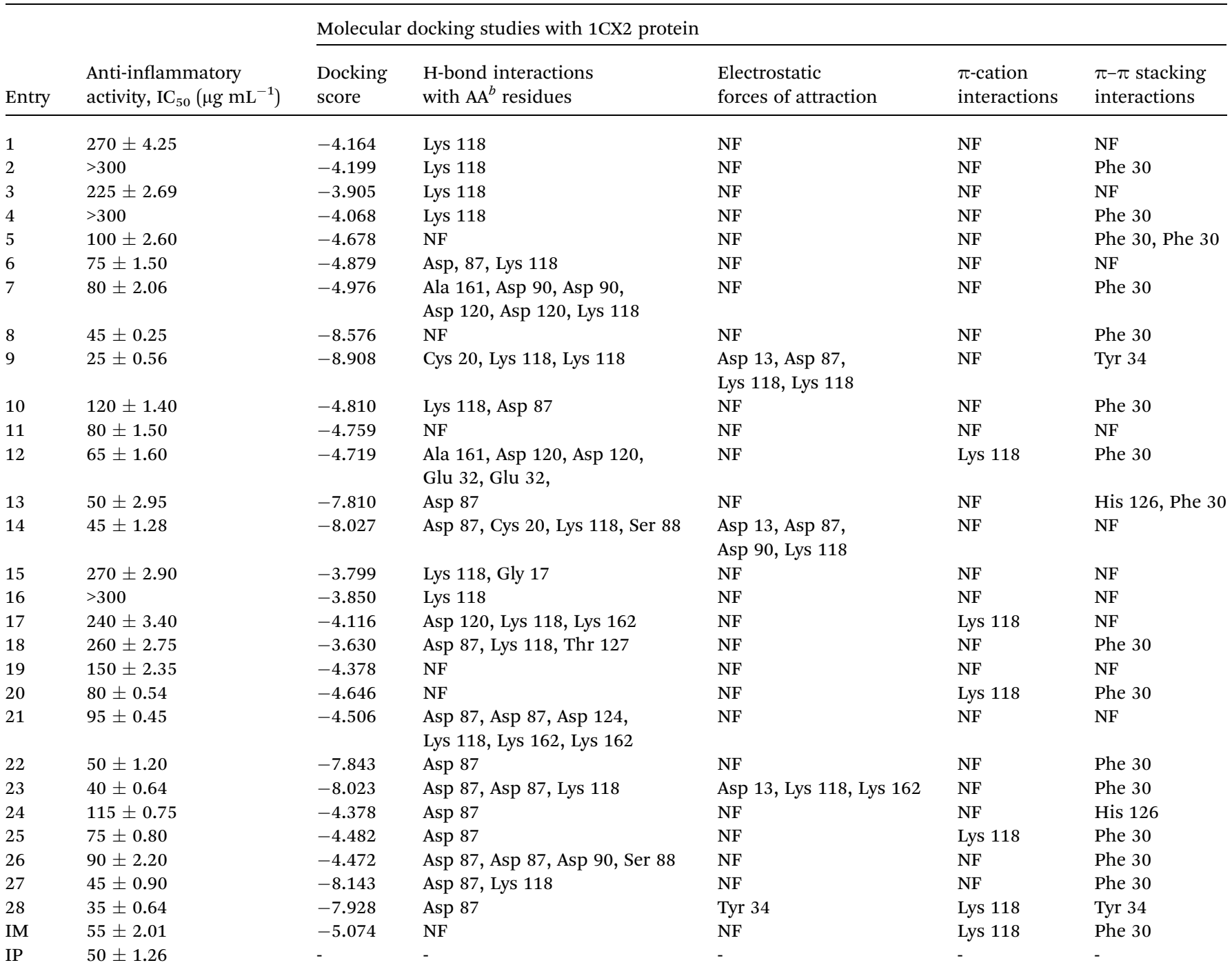

${ }^{a}$ The values are the means of three determinations, the ranges of which are $<5 \%$ of the mean in all cases. ${ }^{b}$ Amino acid; NF: not formed; '-': no activity/not analyzed, IM = indomethacin, IP = ibuprofen.

is a powerful EWG is better at enhancing the anti-inflammatory activity than $\mathrm{Cl}$.

2.2.3. Antimicrobial activity. The efficacy of the synthesized compounds as antimicrobials was tested in antibacterial ${ }^{40}$ studies against different strains of pathogen using both Gram negative bacteria, namely Escherichia coli (E. coli), and Gram positive bacteria, Staphylococcus aureus ( $S$. aureus), and in antifungal $^{41}$ studies against Fusarium moniliforme (F. moniliforme) and Aspergillus niger (A. niger). The results obtained as the zone of inhibition $(\mathrm{mm})$ are presented in Table 3. Streptomycin (SM) and bavistin (BS) served as the standard drugs for the antibacterial and antifungal studies, respectively.

Most of the synthesized compounds showed promising antimicrobial activity with few exceptions. The results of the antimicrobial studies showed that all the analogues exhibited the same trend for both antibacterial and antifungal activity. The quinazolinone-amino acid conjugates $(1,2,15$ and 16) exhibited a much smaller zone of inhibition. When C-terminal benzyl ester/methyl ester groups were converted into hydrazides $(4,5,17$ and 18), there was a slight enhancement in the activity. This may be due to the increase in the polarity of the compounds, which would help the molecule to penetrate more through the cell membrane of microbes and thereby inactivate them..$^{20}$ There was a drastic enhancement in the activity when the hydrazides were converted into hydrazones and we observed that the nature of the substituents present on the phenyl ring affected the biological activity of the compounds to a greater extent.

Among the bis-hydrazones, the compounds with hydroxyl groups $(7,12,21$ and 26$)$ and nitro groups $(9,14,23$ and 28$)$ on the phenyl ring showed potent antimicrobial activity compared to the standard drugs. Compounds bearing methoxy $(\mathbf{6}, \mathbf{1 1}, 20$ and 25) and chloro $(8,13,22$ and 27$)$ groups showed moderate antibacterial properties. Those compounds $(5,10,19$ and 24) 
Table 3 Antimicrobial activity and molecular docking studies of the synthesized analogues with 2VF5

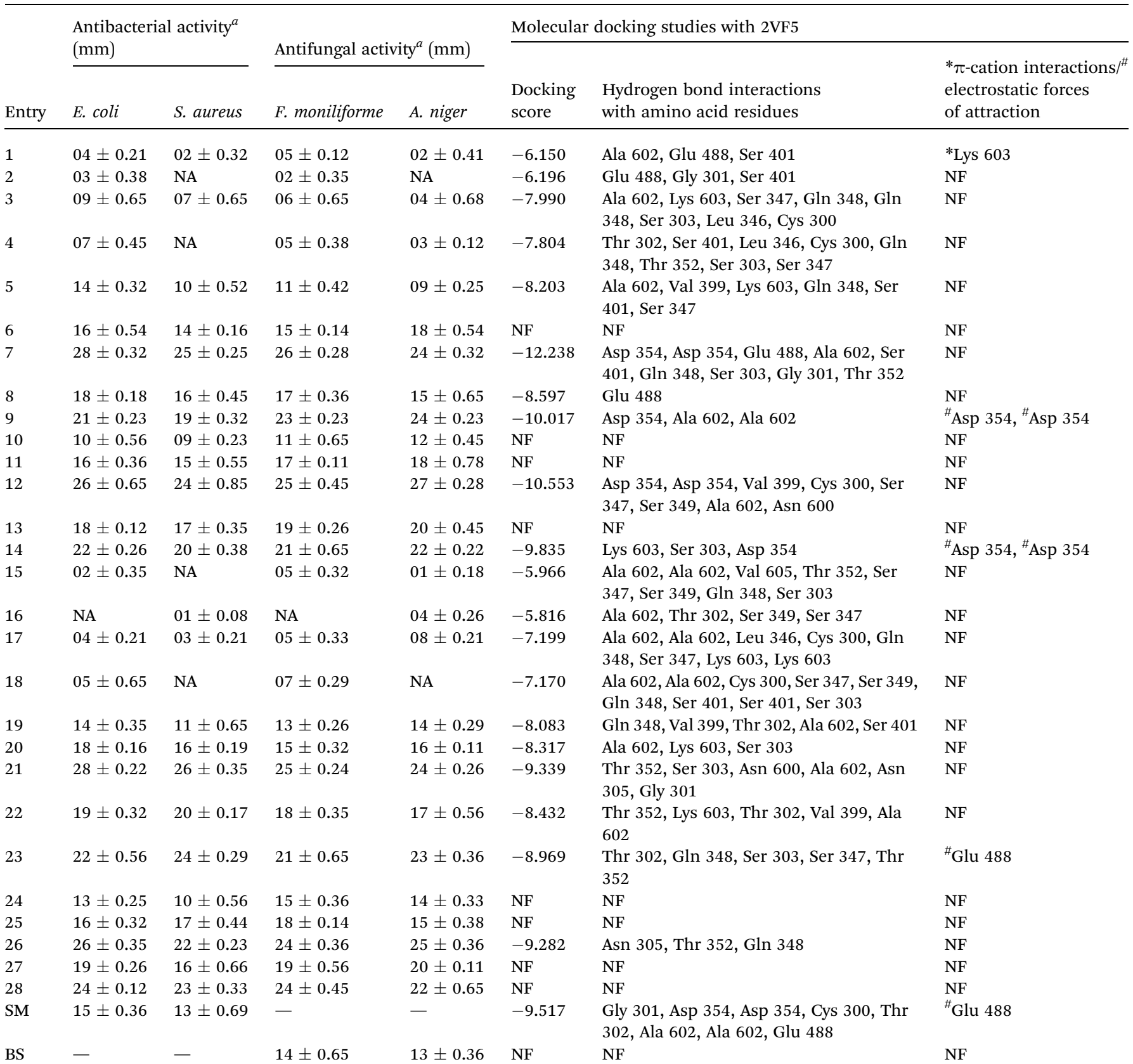

${ }^{a}$ The values are the means of three determinations, the ranges of which are $<5 \%$ of the mean in all cases, $\mathrm{NF}=$ not formed, $\mathrm{SM}=\mathrm{streptomycin}$, $\mathrm{BS}=$ bavistin.

which did not have any substituents on the phenyl ring showed the lowest activity. Thus the order of activity based on the groups attached to the phenyl ring of hydrazone derivatives was found to be $\mathrm{OH}>\mathrm{NO}_{2}>\mathrm{Cl}>\mathrm{OCH}_{3}>\mathrm{H}$. An increase in the alkyl chain length of quinazolinone caused a slight decrease in the antimicrobial activity which is in good agreement with our earlier report. ${ }^{20}$ Replacement of Asp with Glu resulted in a slight decrease in the antimicrobial properties which may be attributed to the increase in hydrophobicity caused by the longer carbon chain in Glu.

\subsection{Molecular docking studies}

The results of the molecular docking studies of the title compounds with respect to the antioxidant, anti-inflammatory and antimicrobial properties are presented below.

Molecular docking was performed on the active site of tyrosine kinase (PDB ID: 2HCK) with the synthesized ligands (1-28) in order to determine the possible binding interactions of highly potent molecules. Most of the compounds showed good docking scores and potent interactions with different amino acid residues and the results are tabulated in Table 1. Among 
the series of compounds, those possessing EDGs, especially hydroxyl groups $(7,12,21$ and 26), gave the highest docking scores. The binding interactions (2D and 3D) of 7, 12, 21 and 26 are displayed in Fig. 2. Compound 7 showed hydrogen bond interactions with Asp 73, Asp 73 and Asn 46 and $\pi$-cation interactions with Arg 76 and compound 12 showed hydrogen
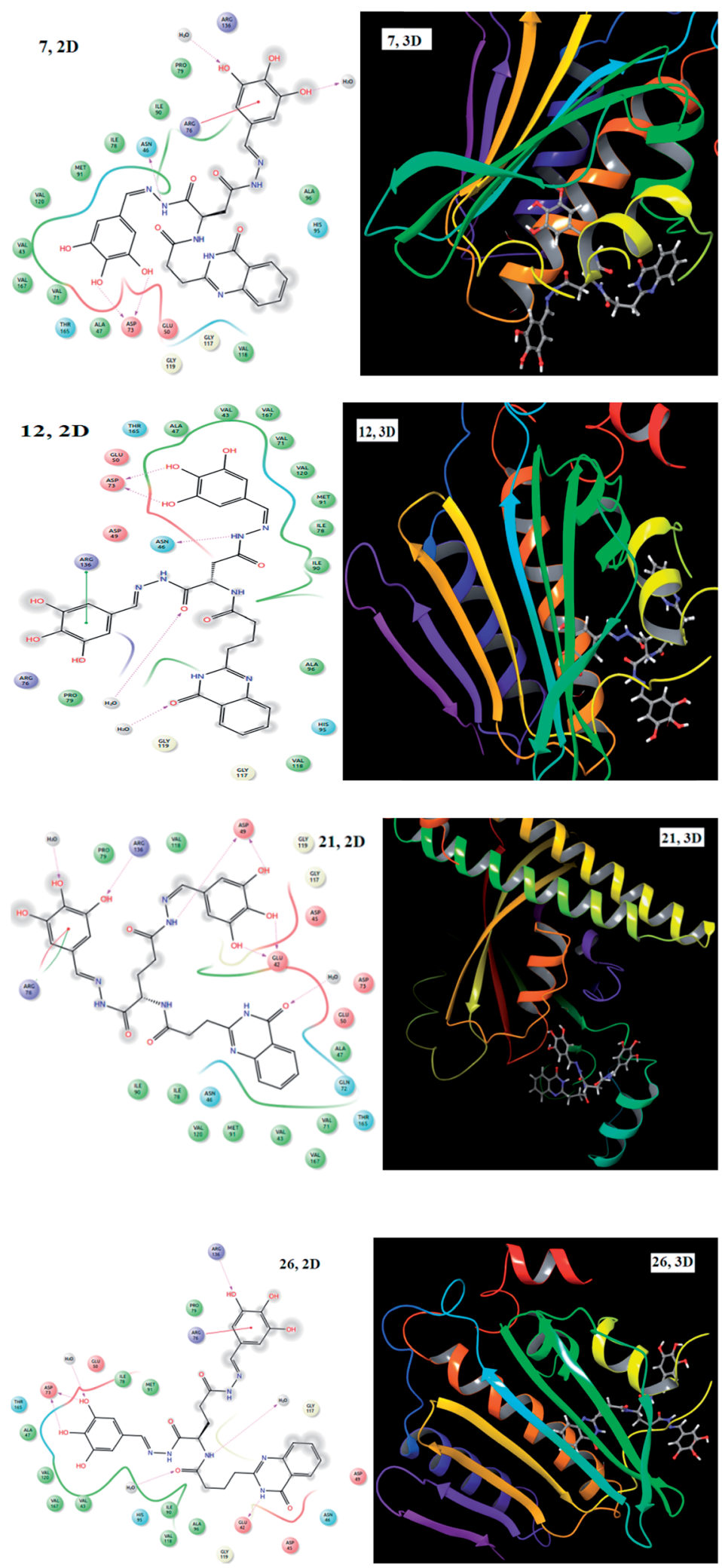

Fig. 2 2D and 3D images of compounds 7, 12, 21 and 26 with 2HCK. 
bond interactions with Asp 73, Asp 73, and Asn 46 and $\pi-\pi$ stacking interactions with Arg 136. Compound 21 showed hydrogen bond interactions with Arg 136, Asp 49, Asp 49, Glu 42 and Glu 42 and $\pi$-cation and $\pi-\pi$ stacking interactions with Arg 76 and compound 26 exhibited hydrogen bond interactions with Arg 136, Asp 73, Asp 73 and Glu 42 and $\pi$-cation
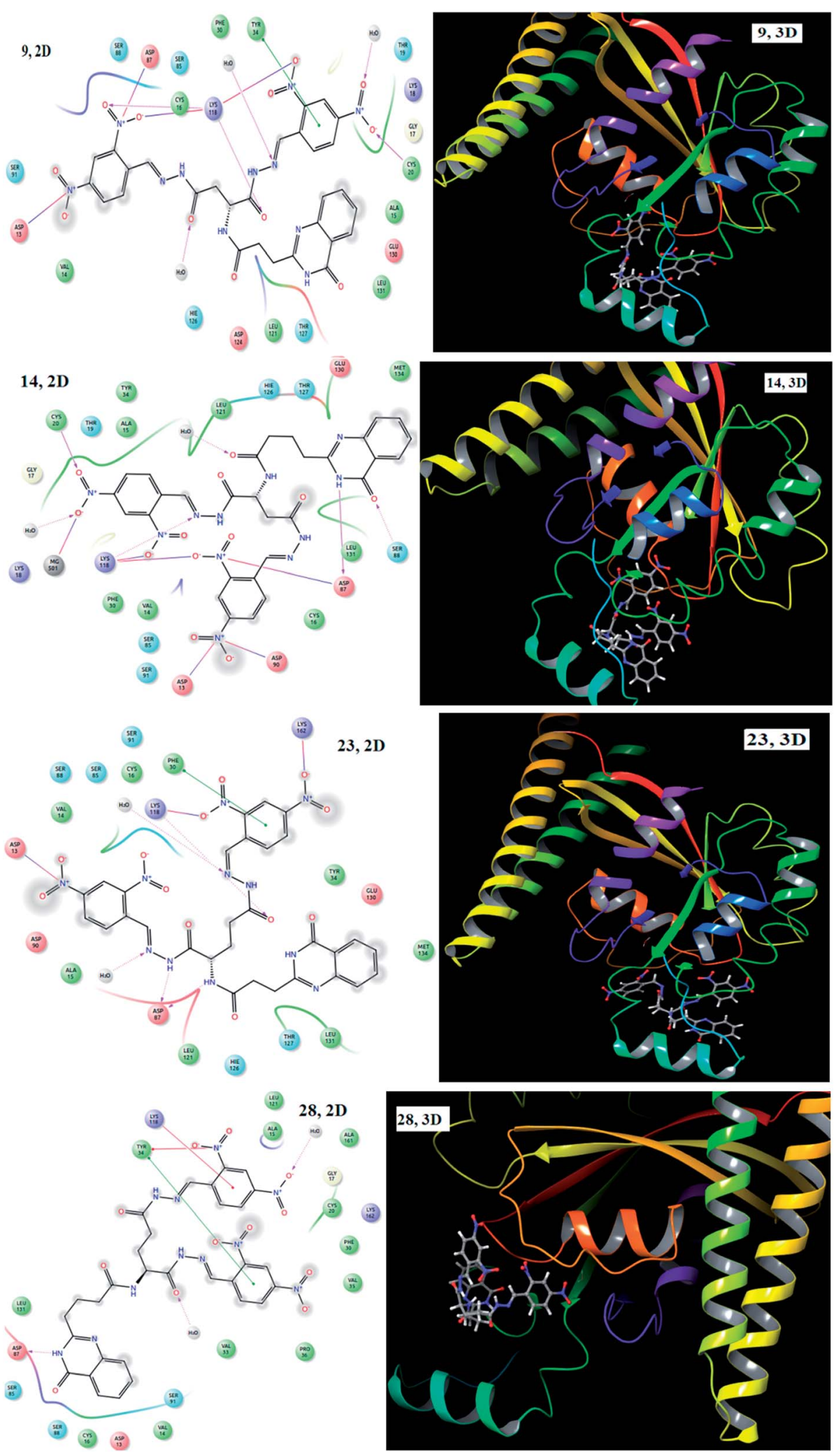

Fig. $32 \mathrm{D}$ and 3D images of compounds 9, 14, 23 and 28 with $1 \mathrm{CX} 2$. 
interactions with Arg 76. These molecules showed the highest docking scores because of the involvement of hydroxyl groups on the phenyl ring in hydrogen bond interactions.
To rationalize the anti-inflammatory potential of the synthesized compounds (1-28), we conducted docking studies on the crystal structure of cyclooxygenase-2 (PDB ID: 1CX2).
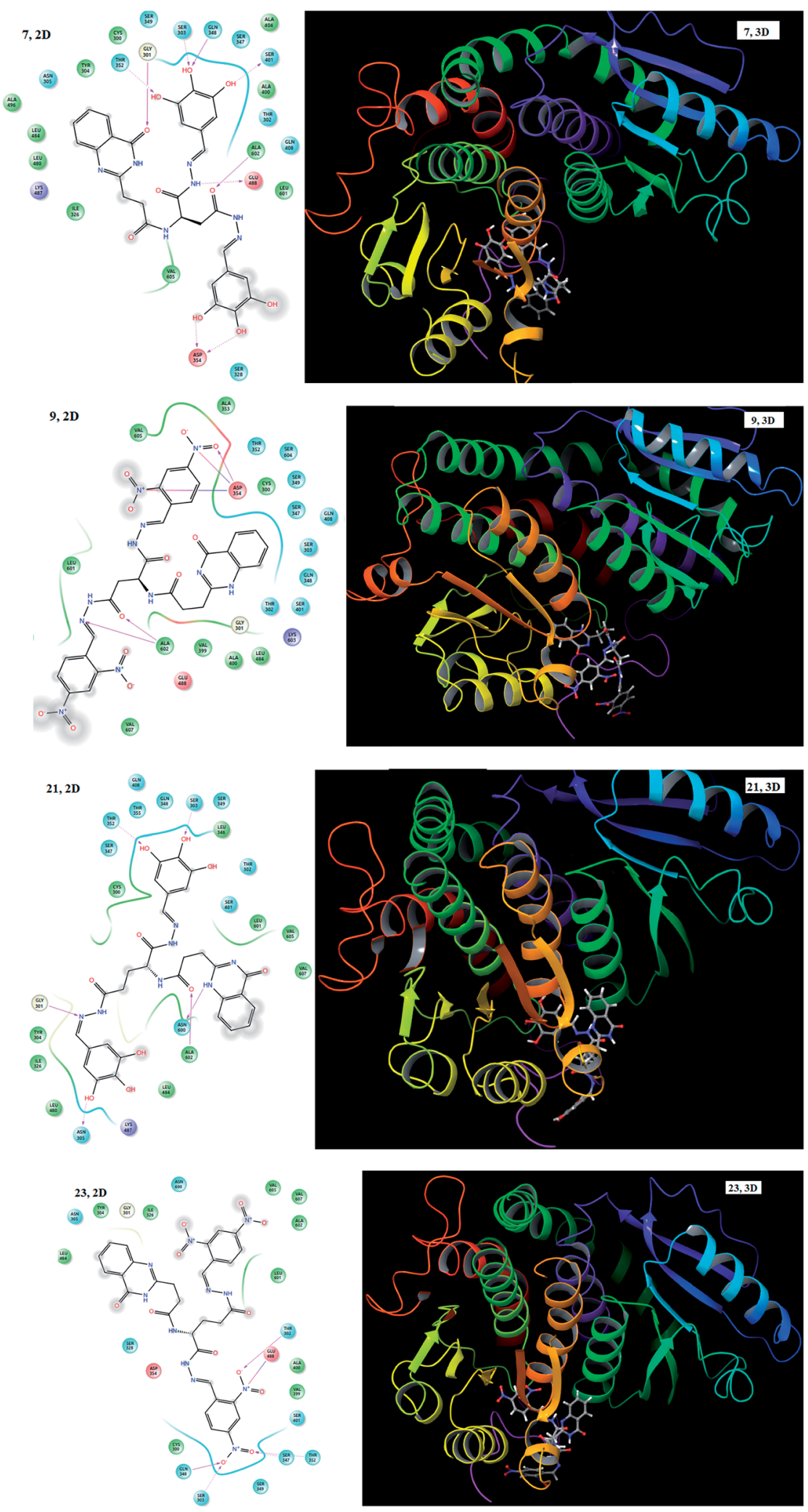

Fig. $42 \mathrm{D}$ and 3D images of compounds 7, 9, 21 and 23 with 2VF5 protein. 
Most of the compounds exhibited a good docking score and different kinds of interaction with amino acid residues and these are tabulated in Table 2. Analogues with EWGs, particularly with $\mathrm{NO}_{2}(\mathbf{9}, 14,23$ and 28) on the phenyl ring, displayed good interactions with amino acid residues and had the highest docking scores. Molecular docking studies provided an interaction map of cyclooxygenase- 2 with 9, 14, 23 and 28 and the results are presented in Fig. 3. Compound $\mathbf{9}$ showed hydrogen bond interactions with Cys 20, Lys 118 and Lys 118, electrostatic forces of attraction with Asp 13, Asp 87, Lys 118 and Lys 188 and $\pi-\pi$ stacking interactions with Tyr 34 ; and compound 14 showed hydrogen bond interactions with Asp 87, Cys 20, Lys 118 and Ser 88 and electrostatic interactions with Asp 13, Asp 87, Asp 90, Lys 118 and Lys 118. Meanwhile, compound 23 displayed hydrogen bond interactions with Asp 87, Asp 87 and Lys 118, electrostatic interactions with Asp 13, Lys 118 and Lys 162 and $\pi-\pi$ stacking interactions with Phe 30 , whereas compound 28 showed hydrogen bond interactions with Asp 87, $\pi$-cation interactions with Lys 118 and Tyr 34 and $\pi-\pi$ stacking interactions with Tyr 34. The $\mathrm{NO}_{2}$ groups present on the phenyl ring involved in electrostatic forces of attraction and $\pi$-cation interactions led to an enhanced docking score.

In order to gain insight into the exact binding location of the ligands with the protein, all the synthesized molecules (1-28) including the standards were subjected to molecular docking with the active site of GlcN-6-P synthase (PDB ID: 2VF5). They showed good binding interactions with the surrounding amino acid residues. The docking score and the interacting amino acids are tabulated in Table 3. Most of the synthesized compounds exhibited well established bonds with one or more amino acids in the receptor active pocket of 2VF5 protein. The potential of the compounds as antimicrobial agents was determined based on the docking scores. The docking scores with 2VF5 protein ranged from -12.238 to -5.816 and the highest negative value indicates the best docked ligand to the targeted site. The 2D and 3D images of compounds 7, 9, 21 and 23 are shown in Fig. 4. Aspartic acid linked hydrazones (7) showed hydrogen bond interactions with Asp 354, Asp 354, Glu 488, Ala 602, Ser 401, Gln 348, Ser 303, Gly 301 and Thr 352 and compound 9 showed hydrogen bond interactions with Asp 354, Ala 602 and Ala 602 and electrostatic forces of interaction with Asp 354 and Asp 354. On the other hand, glutamic acid linked hydrazones (21) displayed hydrogen bond interactions with Thr 352, Ser 303, Asn 600, Ala 602, Asn 305 and Gly 301 and compound 23 showed hydrogen bond interactions with Thr 302, Gln 348, Ser 303, Ser 347 and Thr 352 and electrostatic forces of interaction with Glu 488. The involvement of the hydroxyl groups in hydrogen bond interactions and the nitro groups in electrostatic forces of attraction enhanced the docking scores of these analogues.

\section{Conclusions}

In summary, we have developed a novel class of antioxidant, anti-inflammatory and antimicrobial agent with quinazolinonehydrazones linked via Asp and Glu as connectors. In addition, molecular docking studies were performed on all the synthesized compounds. The correlation between molecular docking studies and biological assays suggested that compounds 6, 7, 11, 12, 20, 21, 25 and 26 with electron donating groups $\left(\mathrm{OH}, \mathrm{OCH}_{3}\right)$ exhibited stronger radical scavenging activity than ascorbic acid and gallic acid. Compounds 8, 9, 13, 14, 22, 23, 27 and 28 with electron withdrawing groups $\left(\mathrm{Cl}, \mathrm{NO}_{2}\right)$ demonstrated better in vitro anti-inflammatory activity than indomethacin and ibuprofen. The compounds with electron donating hydroxyl groups (7, 12, 21 and 26) and electron withdrawing nitro groups $(\mathbf{9}, \mathbf{1 4}, 23$ and 28$)$ exhibited potent antimicrobial properties among this series of compounds.

\section{Conflicts of interest}

There are no conflicts to declare.

\section{Acknowledgements}

The authors gratefully acknowledge the Department of Science and Technology (DST), New Delhi for awarding an Inspire Fellowship and the University Grant Commission (UGC), New Delhi for awarding a BSR Faculty Fellowship and UGC-Post Doctoral Fellowship (PDFSS). We also acknowledge DST-Purse and the computer science department for providing instrumentation facilities and docking facilities, respectively.

\section{References}

1 L. Yao, J. A. Evans and A. Rzhetsky, Trends Biotechnol., 2010, 28, 161-170.

$2 \mathrm{H}$. Terry, Medicinal Chemistry: progress through innovation, Drug discovery world, 2006.

3 P. M. Chandrika, T. Yakaiah, G. Gayatri, K. K. Pranay, B. Narsaiah, U. S. N. Murthy and A. R. R. Rao, Eur. J. Med. Chem., 2010, 45, 78-84.

4 S. G. Rajan, M. T. Hardik, G. Tony, W. Jill, R. Donna, S. Vasudevan and K. V. Kamala, Eur. J. Med. Chem., 2009, 44, 2184-2189.

5 S. Zhu, J. Wang, G. Chandrashekar, E. Smith, X. Liu and Y. Zhang, Eur. J. Med. Chem., 2010, 45, 3864-3869.

6 Z. Maria, G. Silvana, M. Nicola, Z. Giuseppe, S. M. Frank, F. Guido, D. S. Giovambattista and D. M. Carlo, Bioorg. Med. Chem. Lett., 2003, 13, 4427-4430.

7 V. Alagarsamy and U. S. Pathak, Bioorg. Med. Chem., 2007, 15, 3457-3462.

8 M. S. Malamas and J. Millen, J. Med. Chem., 1991, 34, 14921503.

9 G. Giuseppe, B. Gianfranco, V. Loredana, M. M. Ferdinando, et al., Bioorg. Med. Chem. Lett., 2014, 24, 462-466.

10 M. A. Abdulrahman, G. A. Sami, A. E. Hassan, A. Alaa, S. E. Adel, A. A. Hamad and I. E. Hussein, Eur. J. Med. Chem., 2009, 44, 2379-2391.

11 A. S. Natvar, B. D. Ritu, K. P. Rajesh, P. P. Jayanti and C. D. Bharat, J. Saudi Chem. Soc., 2016, 20, S29-S37.

12 B. Kandpal, J. Meshram, I. Mohanram and A. Shaikh, Med. Chem. Res., 2015, 24, 1419-1426. 
13 X. Gao, X. Cai, K. Yan, B. Song, L. Gao and Z. Chen, Molecules, 2007, 12, 2621-2642.

14 V. Alagarsamy, D. Shankar, V. R. Solomon, R. V. Sheorey and P. Parthiban, Acta Pharm., 2009, 59, 75-88.

15 A. Gursoy and N. Karali, Eur. J. Med. Chem., 2003, 38, 633643.

16 A. R. Garrett, E. G. Weagel, A. D. Martinez, M. Heaton, R. A. Robison and K. L. O'Neill, Food Chem., 2014, 158, 490-496.

17 D. Renck, P. Machado, A. A. Souto, L. A. Rosado, T. Erig, M. M. Campos, C. B. Farias, R. Roesler, L. F. S. M. Timmers, O. N. de Souza, D. S. Santos and L. A. Basso, J. Med. Chem., 2013, 56, 8892-8902.

18 H. K. Kumara and D. C. Gowda, Int. J. Pept. Res. Ther., 2017, 23, 259-267.

19 H. K. Kumara, D. M. S. Vardhan, J. S. Kumar and D. C. Gowda, Anti-Inflammatory Anti-Allergy Agents Med. Chem., 2017, 16, 123-133.

20 G. P. Suresha, R. Suhas, W. Kapfo and D. C. Gowda, Eur. J. Med. Chem., 2011, 46, 2530-2540.

21 R. Suhas, S. Chandrashekar, S. M. Anil and D. C. Gowda, Protein Pept. Lett., 2013, 20, 146-155.

22 K. P. Rakesh, H. M. Manukumar and D. C. Gowda, Bioorg. Med. Chem. Lett., 2015, 25, 1072-1077.

23 R. Suhas, S. Chandrashekar and D. C. Gowda, Eur. J. Med. Chem., 2011, 46, 704-711.

24 C. S. Shantharam, D. M. S. Vardhan, R. Suhas, M. B. Sridhara and D. C. Gowda, Eur. J. Med. Chem., 2013, 60, 325-332.

25 A. Sharma, R. Suhas, K. V. Chandana, S. H. Banu and D. C. Gowda, Bioorg. Med. Chem. Lett., 2013, 23, 4096-4098.

26 B. M. Santhosh and P. A. Narasimha, J. Org. Chem., 2001, 66, 9038-9040.
27 A. Wohlrab, R. Lamer and M. S. VanNieuwenhze, J. Am. Chem. Soc., 2007, 129, 4175-4177.

28 J. Fournier, C. Bruneau, H. Dixneuf and S. Lécolier, J. Org. Chem., 1991, 56, 4456-4458.

29 L. Blois, Nature, 1958, 181, 1199-1200.

30 V. Fogliano, V. Verde, G. Randazzo and A. Ritieni, J. Agric. Food Chem., 1999, 47, 1035-1040.

31 I. Glucin, Innovative Food Sci. Emerging Technol., 2010, 11, 210-218.

32 R. Re, N. Pellegrini, A. Proteggente, A. Pannala, M. Yang and C. Rice-Evan, Free Radical Biol. Med., 1999, 26, 1231-1237.

33 K. P. Rakesh, R. Suhas, H. M. Manukumar, S. Chandan and D. C. Gowda, Eur. J. Chem., 2015, 6, 254-260.

34 K. M. Khan, M. Rani, N. Ambreen, A. Ejaz, S. Perveen, S. M. Haider, M. I. Choudhary and W. Voelter, Lett. Drug Des. Discovery, 2012, 9, 135-139.

35 X. Hao, Z. Han, Y. Li, C. Li, X. Wang, X. Zhang, Q. Yang, B. Ma and C. Zhu, Bioorg. Med. Chem. Lett., 2017, 27, 887892.

36 P. K. Sahu, P. K. Sahu, P. L. Sahu and D. D. Agarwal, Bioorg. Med. Chem. Lett., 2016, 26, 1342-1347.

37 K. Sushama, T. Sunil, D. Manoj, S. Jaiprakash and P. Rajendra, Bioorg. Med. Chem. Lett., 2017, 27, 3891-3896.

38 U. A. Shinde, A. S. Phadke, A. M. Nair, A. A. Mungantiwar, V. J. Dikshit and M. N. Saraf, Fitoterapia, 1999, 70, 251-257. 39 P. K. Ashish, D. H. Girish, H. T. Rajesh, H. R. Atish, S. B. Satish and M. K. Vandana, Bioorg. Med. Chem. Lett., 2012, 22, 3445-3448.

40 C. Perez, M. Paul and P. Bazerque, Acta Biol. Med. Exp., 1990, 56, 113-115.

41 I. Singh and V. P. Singh, Phytomorphology, 2000, 50, 151-157. 